\title{
Performance of India's national publicly funded health insurance scheme, Pradhan Mantri Jan Arogaya Yojana (PMJAY), in improving access and financial protection for hospital care: findings from household surveys in Chhattisgarh state
}

Samir Garg ( $\nabla$ koriya@gmail.com )

State Health Resource Centre, Chhattisgarh, India https://orcid.org/0000-0003-4915-0731

Kirtti Kumar Bebarta

State Health Resource Centre, Chhattisgarh, India

Narayan Tripathi

State Health Resource Centre, Chhattisgarh, India

Research article

Keywords: Universal Health Coverage, Publicly Funded Health Insurance, Purchasing, Financial Protection, Access, PMJAY, India, LMIC health systems, Hospital Care

Posted Date: March 2nd, 2020

DOI: https://doi.org/10.21203/rs.3.rs-15599/v1

License: (9) This work is licensed under a Creative Commons Attribution 4.0 International License.

Read Full License

Version of Record: A version of this preprint was published at BMC Public Health on June 16th, 2020. See the published version at https://doi.org/10.1186/s12889-020-09107-4. 


\section{Abstract}

\section{Background:}

A national Publicly Funded Health Insurance (PFHI) scheme called Pradhan Mantri Jan Arogaya Yojana (PMJAY) was launched by government of India in 2018. PMJAY seeks to cover 500 million persons with an annual cover of around 7000 USD per household. PMJAY claims to be the largest government funded health scheme globally and has attracted an international debate as a policy for Universal Health Coverage. India's decade-long experience of the earlier national and state-specific PFHI schemes had shown poor effectiveness in financial protection. Most states in India have completed a year of implementation of PMJAY but no evaluations are available of this important scheme.

\section{Methods:}

The study was designed to find out the effect of enrolment under PMJAY in improving utilisation of hospital services and financial protection in Chhattisgarh which has been a leading state in implementing PFHI in terms of enrolment and claims. The study analyses three repeated cross-sections. Two of the cross-sections are from National Sample Survey (NSS) health rounds - year 2004 when there was no PFHI and 2014 when the older PFHI scheme was in operation. Primary data was collected in 2019-end to cover the first year of PMJAY implementation and it formed the third cross-section. Multivariate analysis was carried out. In addition, Propensity Score Matching and Instrumental Variable method were applied to address the selection problem in insurance.

\section{Results:}

Enrollment under PMJAY or other PFHI schemes did not increase utilisation of hospital-care in Chhattisgarh. Out of Pocket Expenditure (OOPE) and incidence of Catastrophic Health Expenditure did not decrease with enrollment under PMJAY or other PFHI schemes. The size of OOPE was significantly greater for utilisation in private sector, irrespective of enrollment under PMJAY.

\section{Conclusion:}

PMJAY provided substantially larger vertical cover than earlier PFHI schemes in India but it has not been able to improve access or financial protection so far in the state. Though PMJAY is a relatively new scheme, the persistent failure of PFHI schemes over a decade raises doubts about suitability of publicly funded purchasing from private providers in the Indian context. Further research is recommended on such policies in LMIC contexts.

\section{Introduction}

The Ayushman Bharat - Pradhan Mantri Jan Arogaya Yojana (PMJAY) was launched by the central government of India in 2018 as a national Publicly Funded Health Insurance (PFHI) scheme [1, 2, 3]. PFHI schemes have been seen as important means to achieve Universal Health Coverage (UHC) in LMICs, 
including India [4-6]. PMJAY replaces the earlier national PFHI scheme known as the Rashtriya Swasthya Bima Yojana (RSBY) which was in operation for a decade till 2018 [1]. PMJAY claims to be the largest health insurance or assurance scheme in the world, fully financed by government [1]. PMJAY seeks to cover 500 million persons with an annual cover of half a million Indian Rupees (around 7000 USD) per household [1]. It provides a seventeen times larger vertical cover as compared to RSBY [1].

The launch of PMJAY as a key policy in Indian healthcare has been hailed as an important step towards UHC [6]. It has also attracted a vigorous international debate on its merits and suitability for Indian health system [6-13]. The experience of RSBY in India has been well documented and its effectiveness in financial protection was found to be poor [14-24]. The evidence on impact of RSBY in improving access to hospital care has been mixed [15-20]. Some states in India have implemented their own PFHI schemes with cover around 7 times bigger than $\operatorname{RSBY}[1,25,26]$. The recent evidence has shown their poor effectiveness in improving access and financial protection though the evidence from some earlier studies has been more mixed [26-30].

Around $90 \%$ of the states in India had agreed to join hands with the central government to implement PMJAY. Most states have completed a year of implementation of PMJAY [3]. PMJAY, in first year of its implementation, issued 103 million enrollment cards, empanelled 18,236 hospitals and was utilized for over 4.6 million hospitalizations nationally [3]. However, no evaluations are available on how this important scheme has performed in meeting its key objectives.

The stated objectives of PMJAY are to reduce the financial burden on poor and vulnerable groups for access to quality health services [1]. It covers most of the hospital based secondary and tertiary care [1]. PMJAY has defined around 1,370 medical packages covering surgery and treatments including medicines and diagnostics, pre and post-operative care, food and accommodation [1]. PMJAY aims to build on the base provided by RSBY, the national PFHI scheme implemented by many states during 2008 to 2018 [2]. The design of PMJAY differs from RSBY in two key features:

a) Annual sum assured per family under PMJAY is around USD 7000, whereas it was USD 420 under RSBY. Providing an adequately large annual cover has been the central rationale stated by national government for moving from earlier schemes to PMJAY [1]. PMJAY covers a larger range of medical procedures as compared to RSBY.

b) PMJAY covers all the individuals in households classified as poor or vulnerable under the national census. The eligibility under RSBY was relatively restricted as it did not allow more than 5 members per family to get enrolled [1, 3].

Like RSBY, patients enrolled under PMJAY are also not supposed to pay any part of the healthcare cost at any stage $[1,2,3]$. The services under PMJAY are expected to be completely free for the enrolled persons and "cash-less" at the point of care [1,2]. The implementation arrangements of PMJAY are similar to RSBY or state based PFHI schemes [1, 2, 3]. Under PMJAY, states empanel a mix of private and public hospitals to provide a package of in-patient services at pre-defined prices. Some states engage private or 
public insurance firms as intermediaries. Other state governments set up their own 'Trusts' to as a purchaser organisation $[1,3]$.

Chhattisgarh state in central India has been among the leading states in implementing PMJAY in terms of population-enrolment as well as utilisation [3]. Chhattisgarh was a leading state in implementing RSBY as well, earlier [19]. The state started implementing PFHI in form of RSBY in 2009 [19]. RSBY covered the poor households and provided them an annual cover of 420 USD per family. In 2012, Chhattisgarh expanded the population coverage under PFHI by providing additional state funding for covering the nonpoor households [19]. The implementation of PMJAY in Chhattisgarh state started from September 2018 [3]. While PMJAY covered the poor, the non-poor were covered through another smaller PFHI scheme known as Mukhyamantri Swasthya Bima Yojana (MSBY) [31]. PMJAY had an annual cover of around 7000 USD per family whereas MSBY cover was much smaller at 700 USD per family. Around $90 \%$ of the households and $70 \%$ of the individuals living in the state were enrolled under the two schemes with PMJAY contributing to around two-third of the individuals covered [19, 31]. There were 937 hospitals empanelled and a majority of them were for-profit private providers [32]. Private providers accounted for around $85 \%$ of the claim amount under PMJAY, as was the case under RSBY in Chhattisgarh [33]. The above feature is a continuation of pattern prevalent under earlier PFHI schemes in Chhattisgarh and most states in India [26].

This study is aimed at evaluating the performance of PMJAY in improving utilisation and financial protection for hospital care in Chhattisgarh state.

\section{Methods}

For evaluating PFHI schemes, literature recommends that using observations of more than one time is ideal, with one measurement before the insurance scheme began [34]. This study uses three repeated cross-sections. It utilized the opportunity available through the dataset of the National Sample Survey (NSS) of India in form of its two cross-sectional datasets. The $60^{\text {th }}$ round of NSS provides data on hospital care and OOPE for year 2004, which was before PFHI programmes were introduced in any state of India $[35,36]$. The $71^{\text {st }}$ round of NSS in 2014 provides data when RSBY i.e. the scheme with 420 USD annual cover per family was in operation [37-39]. Since there was no household survey available for period after implementation of PMJAY scheme started in September, 2018, a primary survey was carried out in Chhattisgarh in October-November 2019, to collect data on hospital care that took place during first year of implementation of PMJAY. The primary survey of 2019 was carried out on NSS lines. Table 1 provides a summary of PFHI schemes at the three cross-sections.

\section{Table 1: PFHI Schemes and Annual Cover in Chhattisgarh State: three cross-sections}




\begin{tabular}{llll} 
Year & $\begin{array}{l}\text { PFHI } \\
\text { Scheme }\end{array}$ & $\begin{array}{l}\text { Annual Cover per } \\
\text { family }\end{array}$ & Eligible group \\
\hline 2004 & None & None & None \\
\hline 2014 & RSBY & USD 420 & $\begin{array}{l}\text { a) Poor Households (supported by central } \\
\text { government funding) } \\
\text { b) Non-Poor Households (fully funded by state } \\
\text { government) }\end{array}$
\end{tabular}

\begin{tabular}{|c|c|c|c|}
\hline \multirow[t]{2}{*}{2019} & PMJAY & USD 7000 & $\begin{array}{l}\text { Poor Households (supported by central gover } \\
\text { funding) }\end{array}$ \\
\hline & MSBY & USD 700 & $\begin{array}{l}\text { Non-Poor Households (fully funded by state } \\
\text { government) }\end{array}$ \\
\hline
\end{tabular}

The primary survey in 2019 followed a two-stage stratified sampling similar to NSS. A detailed note on the sample design is available in NSS documents [35-39]. In Chhattisgarh, NSS survey covered 6375 individuals in 2004 and 7651 individuals in 2014. The primary survey carried out in Chhattisgarh in 2019 covered 15361 individuals. Since the main objective of the study was to measure the change in financial protection for hospital care, an adequate number of hospitalization episodes was needed in the sample. For a detectable difference of $5 \%$ at $95 \%$ confidence and a design effect of 1.5 , a requirement of around 570 hospitalization episodes was calculated. The actual number of hospitalization episodes covered in the NSS sample was 556 and 817 for year 2004 and 2014 respectively. The 2019 survey was able to cover 924 hospitalisations. The size of sample available was therefore adequate to detect difference of $5 \%$.

Financial Protection was measured in terms of Catastrophic Health Expenditure (CHE) as proposed by Wagstaff and Doorslaer [40]. Out of Pocket Expenditure (OOPE) was calculated for each episode by adding medical expenses and expenses on transportation and deducting any cash-reimbursements received by the patient. OOPE amounts for 2004 and 2019 were adjusted at 2014 prices for valid comparison, as done by recent studies $[26,41]$. For the above adjustment, price deflators for rural (agricultural labour) and urban areas (industrial workers) were used [41, 42]. The survey collected data on usual monthly consumption expenditure and it was multiplied by twelve to calculate the Usual Annual Consumption Expenditure. Recent studies analyzing the NSS datasets have used the same procedure for calculating Annual Household Consumption Expenditure [16,26]. Thresholds of $10 \%, 25 \%$ and $40 \%$ of concerned household's Annual Consumption Expenditure were taken for CHE and named CHE10, CHE25 and CHE40 respectively. Improvement in access to hospital care was assessed in terms of change in utilisation of hospital care.

The survey data was analysed using STATA V.14. Multivariate analysis was carried out to find effect of PMJAY on utilisation, OOPE and CHE. It compared those enrolled under PMJAY with the rest. This analysis was repeated to find out effect of enrollment under any PFHI scheme - PMJAY, MSBY or RSBY, 
by comparing with the non-insured individuals. The list of variables in the study is given in Additional File, S1.

Ordinary Least Squares (OLS) was applied for continuous outcome variables (OOPE, Log of OOPE). Probit model was used for binary outcome variables (CHE). For robustness, this was compared with the Average Treatment Effect on the Treated (ATET) under Propensity Score Matching (PSM) modeling. PSM and other forms of 'matching' have been used for evaluating PFHI, including in India $[16,20]$.

In addition to the above, multivariate analysis for OOPE and CHE was repeated using the Instrumental Variable (IV) approach. This additional analysis was carried out to address the potential selection problem or endogeneity, known to be a common issue while finding out the effect of insurance on economic outcomes like OOPE [34, 43,44]. Instrumental Variable (IV) method has been recommended as a robust solution to the potential problem of endogeneity [34, 43-46]. IV method has been applied in evaluations of impact of PFHI schemes on OOPE and CHE in India, Mexico, China and Ghana [26, 44, 47, 48].

Two-stage least squares (2sls) was applied as IV model for OOPE and Two-step IV Probit for CHE [26, 46, 49]. Wu-Hausman test for 2sls and Wald test of exogeneity for IV Probit were conducted to test for endogeneity. 'Marital-status' was used as an instrumental variable because it satisfied both the criteria for a suitable IV - it was associated with scheme-enrolment and was not expected to have a direct impact on outcome i.e. OOPE. Over-identification restriction tests were applied to check the validity of IV model chosen [49]. The results of the above tests have been reported along with the regression results. A brief note on endogeneity and IV approach is given in Additional File, S2.

Significance was taken at $95 \%(p<0.05)$.

\section{Findings}

The sample profile is given in Additional File S3.

Enrollment under PFHI: Enrollment rate under PFHI has increased in Chhattisgarh over the years. Table 2 provides the scheme-wise enrollment.

Table 2: Enrolment of individuals under different PFHI schemes in Chhattisgarh 
Proportion of individuals (\%) enrolled under different PFHI schemes in Chhattisgarh with $95 \% \mathrm{Cl}$ in 0

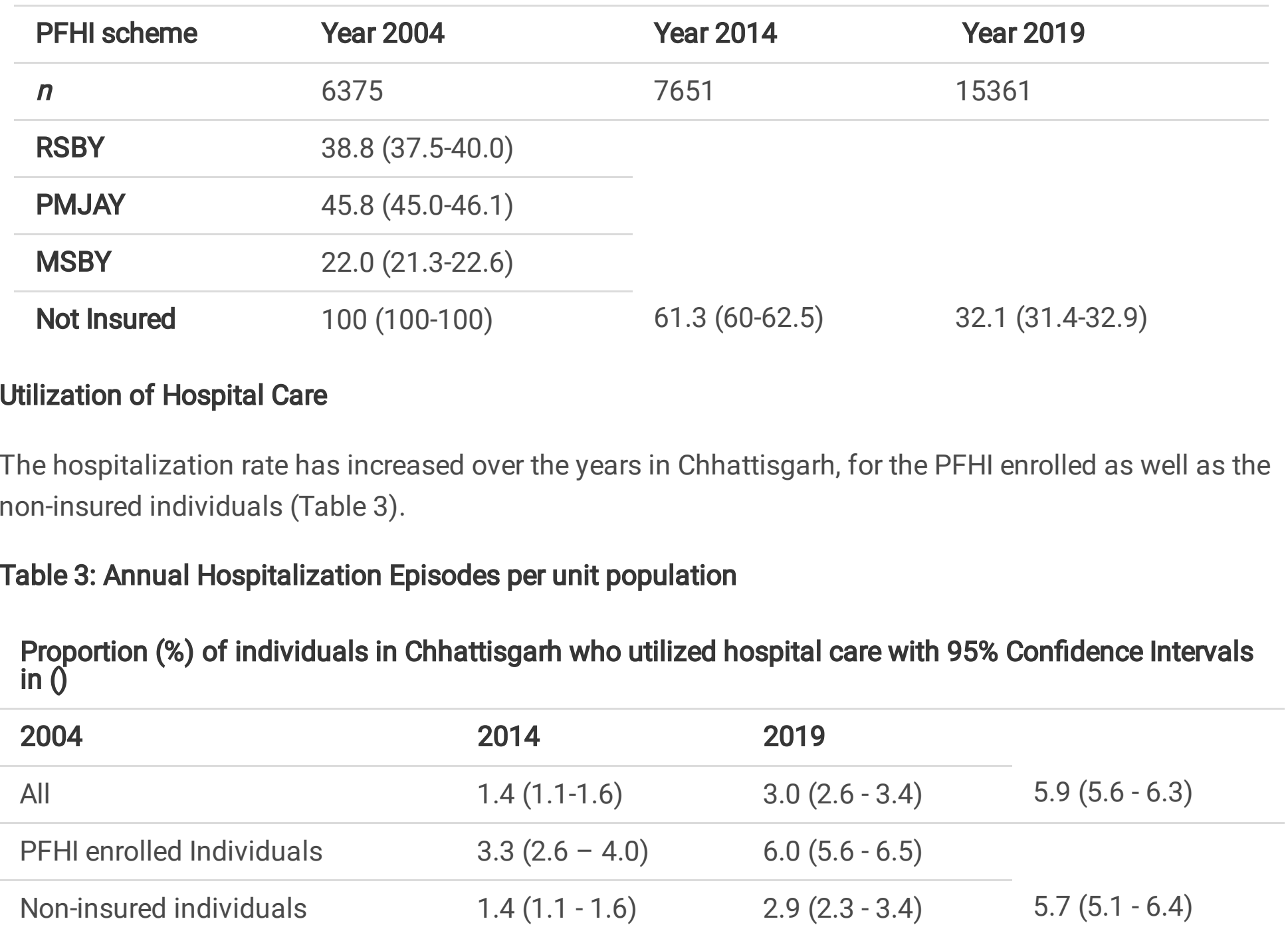

The naïve Probit model as well as PSM showed no significant association between hospitalization and PMJAY-enrollment in Chhattisgarh (Additional File S4). However, utilisation was negatively associated with PFHI-enrolment according to the naïve model (Additional File S4). When PSM was applied, it showed that the effect of PFHI-enrollment on utilisation was almost negligible. Table 4 provides a summary of findings on effect of enrollment on utilisation.

Table 4: Effect of enrolment under PMJAY and PFHI on Utilisation of Hospital Care - Results of Naïve (Probit) model and PSM model

\begin{tabular}{lllll} 
Model & PMJAY & \multicolumn{3}{l}{ PFHI } \\
\cline { 1 - 4 } Coeff. & $\mathrm{p}$ & Coeff. & $\mathrm{P}$ & \\
\cline { 1 - 4 } Probit & -0.02 & 0.54 & $-0.17^{*}$ & $<0.01$ \\
\hline PSM & 0.003 & 0.33 & $-0.01^{*}$ & $<0.01$
\end{tabular}


Choice of Provider. Among hospitalizations in each survey-round, more than $50 \%$ had utilized public sector. In 2019, public sector accounted for over $60 \%$ of the utilisation. The share of private sector in the hospitalizations of the PFHI-enrolled increased from 2014 to 2019 while it declined for the non-insured during that period (Table 5).

Table 5: Share of Private sector in Hospital Utilisation

Proportion of episodes in private hospitals (\%) with $95 \% \mathrm{Cl}$ in 0

\begin{tabular}{llll}
\hline Insurance Status & Year 2004 & Year 2014 & Year 2019 \\
\cline { 1 - 1 } $\mathbf{n}$ & 556 & 817 & 924 \\
\hline All & $47.5(43.4$ to 51.7$)$ & $44.8(41.5$ to 48.2$)$ & $39.9(36.7$ to 43.1$)$ \\
\hline PFHI insured & $32.8(28.1$ to 37.5$)$ & $45.1(41.1-49)$ & \\
\cline { 1 - 3 } Not Insured & $47.5(43.4$ to 51.7$)$ & $53.6(49.1$ to 58$)$ & $28.6(23.3-33.9)$
\end{tabular}

\section{OOPE and Financial Protection}

The mean OOPE for utilizing hospital-care in private sector was many times larger than in public sector. This was true for the PFHI-enrolled and also for the non-insured (Table 6). The mean OOPE was similar for the PMJAY-enrolled and for the non-insured.

Table 6: Mean OOPE under different PFHI schemes 
Mean OOPE for Hospitalisation Episodes (in INR) with $95 \% \mathrm{Cl}$ in $\mathrm{O}$

\begin{tabular}{|c|c|c|c|c|}
\hline $\begin{array}{l}\text { PFHI } \\
\text { Scheme }\end{array}$ & $\begin{array}{l}\text { Type of } \\
\text { Hospital }\end{array}$ & Year 2004 & Year 2014 & Year 2019 \\
\hline $\mathbf{n}$ & 556 & 817 & 924 & \\
\hline \multirow[t]{2}{*}{ All } & Public & 8603 (6818-10388) & 3491 (2844-4137) & 3101 (2281-3922) \\
\hline & Private & $\begin{array}{l}15280(12195- \\
18365)\end{array}$ & $\begin{array}{l}22929 \text { (18481- } \\
27377)\end{array}$ & $\begin{array}{l}26108(18622- \\
33595)\end{array}$ \\
\hline \multirow[t]{2}{*}{ RSBY } & Public & 2633 (1669-3598) & & \\
\hline & Private & $\begin{array}{l}26326 \text { (17734- } \\
34918)\end{array}$ & & \\
\hline \multirow[t]{2}{*}{ PMJAY } & Public & 3078 (1928-4228) & & \\
\hline & Private & $\begin{array}{l}19375(11305- \\
27447)\end{array}$ & & \\
\hline \multirow[t]{2}{*}{ MSBY } & Public & $3506(920-6092)$ & & \\
\hline & Private & $\begin{array}{l}41154(20689- \\
61619)\end{array}$ & & \\
\hline \multirow[t]{2}{*}{ Not enrolled } & Public & 2912 (2213-3749) & $1800(1537-2000)$ & $2974(1675-4272)$ \\
\hline & Private & 7922 (6647-9407) & $\begin{array}{l}13650(10500- \\
16778)\end{array}$ & $\begin{array}{l}20261 \text { (11689- } \\
28843)\end{array}$ \\
\hline
\end{tabular}

Median OOPE in the private sector was many times greater than in public sector (Table 7). According to descriptive findings, median OOPE in private hospitals for the PMJAY-enrolled was $17 \%$ lower than for the non-insured.

Table 7: Median OOPE for Hospitalisation Episodes 
Median OOPE for Hospitalisation Episodes (in INR) with $95 \% \mathrm{Cl}$ in 0

\begin{tabular}{|c|c|c|c|c|}
\hline $\begin{array}{l}\text { PFHI } \\
\text { scheme }\end{array}$ & $\begin{array}{l}\text { Type of } \\
\text { Hospital }\end{array}$ & Year 2004 & Year 2014 & Year 2019 \\
\hline $\mathbf{n}$ & 556 & 817 & 924 & \\
\hline \multirow[t]{2}{*}{ All } & Public & 2912 (2213-3749) & $1100(903-1350)$ & $378(378-606)$ \\
\hline & Private & 7922 (6647-9407) & $\begin{array}{l}12450(10500- \\
15222)\end{array}$ & $\begin{array}{l}7575(7299- \\
10253)\end{array}$ \\
\hline \multirow[t]{2}{*}{ RSBY } & Public & $570(400-800)$ & & \\
\hline & Private & $\begin{array}{l}10650(9510- \\
15093)\end{array}$ & & \\
\hline \multirow[t]{2}{*}{ PMJAY } & Public & $530(379-758)$ & & \\
\hline & Private & 7299 (3788-9032) & & \\
\hline \multirow[t]{2}{*}{ MSBY } & Public & 303 (151-496) & & \\
\hline & Private & $\begin{array}{l}13447 \text { (7299- } \\
18138)\end{array}$ & & \\
\hline \multirow[t]{2}{*}{ Not enrolled } & Public & 2912 (2213-3749) & $1800(1537-2000)$ & 417 (298-703) \\
\hline & Private & 7922 (6647-9407) & $\begin{array}{l}13650 \text { (10500- } \\
16778)\end{array}$ & $\begin{array}{l}8759(7575- \\
11990)\end{array}$ \\
\hline
\end{tabular}

CHE25 incidence: CHE25 incidence was many times greater for utilisation in private sector as compared to public sector. CHE25 incidence was similar for the PMJAY-enrolled and for the non-insured (Table 7).

Table 7: Incidence of CHE25 for Hospitalisation 
Proportion of incurred CHE25 for Hospitalisation Episode (\%) with $95 \% \mathrm{Cl}$ in 0

\begin{tabular}{|c|c|c|c|c|}
\hline PFHI scheme & Type of Hospital & Year 2004 & Year 2014 & Year 2019 \\
\hline $\mathbf{n}$ & 556 & 817 & 924 & \\
\hline \multirow[t]{2}{*}{ All } & Public & $14.9(10.6-19.3)$ & $4.4(2.5-6.3)$ & $7.2(5.0-9.4)$ \\
\hline & Private & $27.6(22.6-32.9)$ & $32.1(27.6-36.6)$ & $39.4(34.4-44.5)$ \\
\hline \multirow[t]{2}{*}{ RSBY } & Public & $4.8(2.0-7.7)$ & & \\
\hline & Private & $34.4(26.9-41.8)$ & & \\
\hline \multirow[t]{2}{*}{ PMJAY } & Public & $7.6(4.5-11.0)$ & & \\
\hline & Private & $43.6(36.3-51.4)$ & & \\
\hline \multirow[t]{2}{*}{ MSBY } & Public & $3.8(0.5-8.1)$ & & \\
\hline & Private & $32.4(23.4-41.4)$ & & \\
\hline \multirow[t]{2}{*}{ Not enrolled } & Public & $14.9(10.6-19.3)$ & $4.0(1.4-6.6)$ & $7.9(4.2-11.7)$ \\
\hline & Private & $27.6(22.6-32.9)$ & $30.7(25.0-36.4)$ & $39.5(28.6-50.4)$ \\
\hline
\end{tabular}

Determinants of Size of OOPE and CHE: Table 8 provides a summary of findings regarding the effect of PMJAY and all PFHI schemes respectively on OOPE and CHE. The naïve OLS model showed no association between the size of OOPE and enrollment under PMJAY or any of the PFHI schemes. The above finding did not change under PSM and IV models.

The naïve as well as the PSM model showed a significant but small reduction in Log of OOPE associated with PMJAY enrolment. The IV model however showed no association between Log of OOPE and PMJAY enrolment.

Table 8: Effect of enrolment under PMJAY and PFHI on OOPE and CHE for Hospital Care - Results of Naïve (Probit) model, PSM and IV Models 


\begin{tabular}{|c|c|c|c|c|c|c|c|}
\hline \multirow{2}{*}{$\begin{array}{l}\text { Variable } \\
\text { Coeff. }\end{array}$} & \multirow{2}{*}{$\begin{array}{l}\text { Scheme } \\
\text { P }\end{array}$} & \multicolumn{2}{|c|}{ OLS Model } & \multicolumn{2}{|c|}{ Probit Model } & \multicolumn{2}{|c|}{ PSM Model (ATET) } \\
\hline & & Coeff. & $\mathrm{p}$ & Coeff. & $\mathrm{p}$ & Coeff. & $\mathrm{P}$ \\
\hline \multirow[t]{2}{*}{ OOPE } & PMJAY & -4287 & 0.09 & -4614 & 0.20 & 48734 & 0.59 \\
\hline & PFHI & -87 & 0.97 & -1066 & 0.73 & 17315 & 0.72 \\
\hline \multirow[t]{2}{*}{ Log of OOPE } & PMJAY & $-0.45^{*}$ & $<0.01$ & $-0.37 *$ & $<0.01$ & -0.48 & 0.86 \\
\hline & PFHI & $-0.34^{*}$ & $<0.01$ & $-0.50 *$ & $<0.01$ & 1.01 & 0.53 \\
\hline \multirow[t]{2}{*}{ CHE10 } & PMJAY & 0.08 & 0.35 & 0.02 & 0.52 & -4.39 & 0.28 \\
\hline & PFHI & -0.07 & 0.29 & 0.003 & 0.90 & -2.23 & 0.23 \\
\hline \multirow[t]{2}{*}{ CHE25 } & PMJAY & $0.22 *$ & 0.01 & 0.05 & 0.08 & -2.03 & 0.54 \\
\hline & PFHI & 0.04 & 0.56 & 0.02 & 0.33 & -1.28 & 0.48 \\
\hline \multirow[t]{2}{*}{ CHE40 } & PMJAY & $0.26 *$ & 0.01 & 0.04 & 0.14 & -0.67 & 0.85 \\
\hline & PFHI & 0.05 & 0.55 & 0.01 & 0.36 & -0.68 & 0.74 \\
\hline
\end{tabular}

${ }^{*} p<0.05$

PMJAY enrolment was associated with increase in CHE25 and CHE 40 according to the naïve Probit model. However, the above finding did not hold under PSM and the IV models. CHE10 was not associated with PMJAY or PFHI enrollment under any of the models.

Based on above analysis, we conclude there was either an insignificant or at best a minor reduction in OOPE with PMJAY-enrollment, but none in CHE.

Under all the models, significantly greater OOPE and CHE were likely for utilisation in private sector as compared to public sector. NCDs or Injuries compared to Communicable diseases and hospitalisations longer than 3 days were also associated with greater OOPE or CHE (Additional Files S5 to S14).

The OLS models for OOPE and Log of OOPE is given in Additional Files S5 and S6 respectively. The IV models for OOPE and Log of OOPE is given in Additional Files S7 and S8 respectively. The naïve Probit models for CHE10, CHE25 and CHE40 are given in Additional Files S9, S10 and S11 respectively. The IV Models for CHE10, CHE25 and CHE40 are given in Additional Files S12, S13 and S14 respectively.

For robustness, the above analysis were repeated with the single cross-section data from 2019 primary survey and the pattern of the results remained similar for effect of PMJAY on OOPE or CHE.

\section{Discussion}

The utilisation of hospital care did not increase with enrollment under PMJAY or other PFHI schemes in Chhattisgarh. Some earlier studies have concluded that utilisation increased due to PFHI in India [17, 19, 
20]. The mixed findings could be due to differences in the methods applied and time-periods of different studies. The more recent studies that have applied PSM or IV to address selection issues, have reported no increase in utlisation with PFHI enrolment $[16,26]$.

The current study found that coverage under PMJAY or other PFHI schemes in Chhattisgarh did not reduce OOPE or $\mathrm{CHE}$. The inability of $\mathrm{PFHI}$ in ensuring financial protection for hospital-care is consistent with many other studies of RSBY and other state-level PFHI schemes in India [15-26]. Some studies had suggested that the vertical cover of INR 30,000 (USD 420) annual sum assured per family might be insufficient, thereby causing possibility of CHE under RSBY $[15,19]$. PMJAY design of a seventeen times larger sum assured was expected to reduce OOPE, but the current study found that it failed to do so. A study of Southern states in India had shown that a large cover may not ensure financial protection [26].

Why did OOPE and CHE remain high under PMJAY? The benefit stipulated in PMJAY and other PFHIs was of free cashless service covering pre and post operative care, diagnostics, drugs and transportation. The contracts forbade the hospitals from charging any copayments. Yet, the mechanism of contracting could not prevent private hospitals from taking extra money from patients. The size of OOPE and incidence of $\mathrm{CHE}$ in the current study was several times higher for private-sector hospitalizations irrespective of enrollment under PFHI, as found in earlier studies in India [16, 19, 26]. The likelihood of insurance benefit being appropriated by powerful providers has been a long-standing problem in LMIC contexts [51]. The possibility of 'provider capture' has been pointed out [12]. Researchers have also highlighted the role of unnecessary or costly medical procedures being used by providers under such schemes $[8,12]$.

Some studies have found 'double-billing' by hospitals as a cause of OOPE under PFHI in India [24-25]. 'Double billing' in the context of PFHI has been referred to the situation when hospitals, while claiming the amount for a service from insurance side, also charged illegal copayments from patients for the same service or asked them to buy drugs, diagnostics and consumables from outside [24-26]. Tendencies to charge extra from the patients, despite PFHI cover have been reported from several states of India [24-26]. Studies have recommended that stronger supervision by state authorities, better mechanisms for addressing grievances and a 24-hour helpline should be implemented to address the problem of 'doublebilling' $[15,16,24]$. PMJAY included measures for fraud control and a 24-hour helpline but they seem to be ineffective as far as protecting patients from extra charging is concerned. A recent qualitative study of experiences of patients of utilizing private sector care under PFHI in Chhattisgarh has provided fresh insights about the regulatory failure as well as the normative and cultural contexts contributing to overcharging by private hospitals [52]. We recommend further qualitative research, including on the regulation and purchasing side, to understand the gaps leading to poor financial outcomes under PFHI.

The current study suggests that the main challenges faced by earlier PFHI schemes in India continue to plague PMJAY. This scheme does have a bigger vertical cover and offers a larger range of treatment packages compared to other schemes. But, little else seems to be different in terms of design features or 
implementation arrangements. There seems to be a failure in recognizing the reasons for failures of previous schemes and devising measures to address them in PMJAY.

The study examined the first year of implementation of PMJAY and the scheme would require serious changes if it has to meet its objectives in coming years. PMJAY is a relatively new scheme but India now has more than a decade of experience in implementing PFHI based purchasing. Its persistent lack of success in financial protection indicates the limitations of PFHI strategy in Indian context. Some of the states in India, e.g. Odisha and Delhi, have chosen to stay out of PMJAY and have implemented differently designed health schemes of their own. It might be useful to study such models and compare their outcomes with PMJAY in other states.

The unacceptably high OOPE under PMJAY may be related to provider behavior and continuing poor regulation. There is a growing recognition that governance and control needs to be strong for purchasing to be successful in LMICs $[53,54]$. The relative size of OOPE in private and public sector hospitals, suggests that the share of the public sector could be increased in provisioning to bring down overall OOPE [26]. Further research is recommended on experiences of publicly funded schemes in LMICs that rely on contracting for-profit providers.

Limitations: The NSS dataset does not distinguish between older insurance schemes of Central Government Health Services (CGHS) and Employee State Insurance (ESI) for the formally employed and the current wave of PFHls that were the focus of this study. Other studies have reported that CGHS and ESIS form a very small proportion of PFHI enrollment and do not affect the results materially $[16,19]$.

\section{Conclusions}

The study provides one of the first evaluations of PMJAY, the latest national health insurance programme in India. The evaluation of its first year of implementation suggests that gaps and failures of earlier PFHI schemes have persisted under PMJAY. Just increasing annual sum assured and addition of treatment packages has not given the desired results in improving access or financial protection. Major changes may be necessary in how provisioning is organized for achieving progress towards goals of UHC. Further evaluations of PMJAY and of alternative schemes in other states are recommended along with qualitative studies. PFHI based purchasing seems to have limitations as a policy option in Indian health system context. Studies of national schemes involving publicly funded purchasing are recommended for other LMICs.

\section{Abbreviations}

CHE: Catastrophic health expenditure; CHE10: Catastrophic Health Expenditure computed using the threshold of $10 \%$ of usual annual consumption expenditure; CHE25: Catastrophic Health Expenditure computed using the threshold of $25 \%$ of usual annual consumption expenditure; CHE40: Catastrophic Health Expenditure computed using the threshold of $40 \%$ of usual annual consumption expenditure; $\mathrm{Cl}$ : 
Confidence Interval; INR: Indian Rupee; IV: Instrumental Variable; LMIC: Low and Medium Income Countries NSS: National sample survey; OLS: Ordinary Least Squares OOPE: Out-of-pocket expenditure; PFHI: Public Funded Health Insurance; PMJAY: Pradhan Mantri Jan Arogaya Yojana RSBY: Rashtriya Swasthya Bima Yojana; UHC: Universal Health Coverage; USD: US Dollar 2sls: Two Stage Least Squares

\section{Declarations}

\section{Acknowledgements}

The primary data collection in 2019 was supported by the State Health Resource Centre, Chhattisgarh, India.

\section{Funding}

No funding was obtained for this study.

\section{Consent for Publication}

Not Applicable.

\section{Availability of data and materials}

The secondary dataset used are available at [microdata.gov.in/nada43/index.php/catalog/105] and [microdata.gov.in/nada43/index.php/catalog/135] for 2004 and 2014 rounds of NSS respectively. The combined anonymised dataset, including the 2019 survey is available in public domain at [shsrc.in/cghealth-at-a-glance/study data].

\section{Authors' contributions}

SG contributed to the study design and writing of the manuscript. SG and KB analysed the data. KB, NT and SG contributed to design of tools and supervising the data-collection. All authors have read and approved the manuscript.

\section{Authors' information}

SG works with State Health Resource Centre, Chhattisgarh, India

KB works with State Health Resource Centre, Chhattisgarh, India

NT works with State Health Resource Centre, Chhattisgarh, India

\section{Ethics approval and consent to participate}

The secondary dataset analysed for this article are from the National Sample Survey, $60^{\text {th }}$ and $71^{\text {st }}$ Round, which contains anonymised data in the public domain. The researchers had no access to 
personal identifiable data. The survey is undertaken by the National Sample Survey Office (NSSO) of the Ministry of Statistics and Programme Implementation of the Government of India. Data available in public domain are approved for use for research purpose by Ministry of Statistics and Programme Implementation, Government of India. For the 2019 survey, written informed consent was taken from all respondents and approval was obtained from the Institutional Ethics Committee of State Health Resource Centre, Chhattisgarh. The data was anonymised.

\section{Competing interests}

The authors declare that there are no competing interests.

\section{Author details}

1 State Health Resource Centre, Chhattisgarh, Raipur, India

2 State Health Resource Centre, Chhattisgarh, Raipur, India

3 State Health Resource Centre, Chhattisgarh, Raipur, India

\section{References}

1. Government of India. About Pradhan Mantri Jan Arogaya Yojana (PM-JAY). https://www.pmjay.gov.in/about-pmjay. Accessed September 6, 2019.

2. Government of India. Health benefit packages \& Empanelment criteria for AB-NHPM. https://www.pmjay.gov.in/sites/default/files/2018-07/HBP.pdf. Accessed September 6, 2019.

3. National Health Authority. Annual Report 2018-19 Ayushman Bharat - Pradhan Mantri Jan Arogaya Yojana (PMJAY). https://pmjay.gov.in/sites/default/files/2019-09/Annual\%20Report\%20\%20PMJAY\%20small\%20version_1.pdf. Accessed on 30 th December, 2019.

4. Preker, AS, Lindner, ME, Chernichovsky, D, Schellekens, OP eds. Scaling Up Affordable Health Insurance. The World Bank; 2013. doi:10.1596/978-0-8213-8250-9.

5. Lagomarsino G, Garabrant A, Adyas A, Muga E, Otoo N. Moving towards universal health coverage: health insurance reforms in nine developing countries in Africa and Asia. Lancet. 2012; 380: 933:43. https://doi.org/10.1016/S0140-6736(12)61147-7 PMID: 22959390

6. Horton R. The New Politics of Health in India. thelancet.com. Vol 392, September 15, 2018

7. Chatterjee P. National Health Protection Scheme revealed in India. Lancet. 2018; 391(10120):523524. doi:10.1016/S0140-6736(18)30241-1.

8. Brundtland GH. India's Health Reforms: The Need for Balance. thelancet.com. Published Online September 25, 2018 http://dx.doi.org/10.1016/ S0140-6736(18)32387-0

9. Angell BJ, Prinja S, Gupt A, Jha V, Jan S. The Ayushman Bharat PradhanMantri Jan ArogyaYojana and the path to universal health coverage in India: Overcoming the challenges of stewardship and 
governance. PLoS Med 16(3): e1002759. https://doi.org/10.1371/journal. pmed.1002759 Published: March 7, 2019

10. Barai-Jaitly T, Ghosh S. Role of Government in Funded Health Insurance Schemes. Economic and Political Weekly. 2018; 53(25):7-8.

11. Ghosh, S. Publicly Financed Health Insurance Schemes. Econ Polit Wkly. 2018; 53, Issue No. 23, 09 June, 2018

12. Sanders, D. et al. From primary health care to universal health coverage-one step forward and two steps back. August 2019. The Lancet. 394(10199):619-621. DOI: 1016/S0140-6736(19)31831-8

13. Chatterjee P. Health debate rising around the upcoming Indian election. www.thelancet.com. Vol 393 April 13, 2019

14. Karan A, Yip W, Mahal A. Extending health insurance to the poor in India: An impact evaluation of RashtriyaSwasthyaBimaYojana on out of pocket spending for healthcare. SocSci Med. 2017; 181:8392. doi:10.1016/j.socscimed.2017.03.053.

15. Prinja S, Chauhan A, Karan A, Kaur G, Kumar R. Impact of Publicly Financed Health Insurance Schemes on Healthcare Utilization and Financial Risk Protection in India: A Systematic Review. PLoS ONE 2017; 12(2):e0170996. https://doi.org/10.1371/journal.pone.0170996 PMID: 28151946

16. Ranjan A, Dixit P, Mukhopadhyay I, Sundararaman T. Effectiveness of government strategies for financial protection against costs of hospitalization Care in India. BMC Public Health. 2018; 18(1):501. doi:10.1186/s12889-018-5431-8.

17. Ravi S, Ahluwalia R, Bergkvist S. Health and Morbidity in India (2004-2014). Brookings India Research Paper No. 092016. 2016. Available from: https://www.brookings.edu/wpcontent/uploads/2016/12/201612_health-and-morbidity.pdf. Accessed 15th September,2018.

18. Prinja S, Bahuguna P, Gupta I. et al. Role of insurance in determining utilization of healthcare and financial risk protection in India. PLOS One. Published: February 5, 2019. https://doi.org/10.1371/journal.pone.0211793

19. Nandi S, Schneider H, Dixit P. Hospital utilization and out of pocket expenditure in public and private sectors under the universal government health insurance scheme in Chhattisgarh State, India: Lessons for universal health coverage. PLoS One. 2017; 12(11):e0187904. doi:10.1371/journal.pone.0187904.

20. Ghosh S and Gupta N. Targeting and Effects of Rashtriya Swasthya BimaYojana on Access to Care and Financial Protection. Economic and Political Weekly. 2017; January 28, 2017 vol LII No 4. 61-70

21. Selvaraj $S$, Karan A. Why publicly-financed health insurance schemes are ineffective in providing financial risk protection. Economic and Political Weekly. 2012; 47(11):61-8.

22. Devadasan N, Seshadri T, Trivedi M, Criel B. Promoting universal financial protection: evidence from the Rashtriya Swasthya Bima Yojana (RSBY) in Gujarat, India. Heal Res Policy Syst. 2013; 11(1):29. doi:10.1186/1478-4505-11-29.

23. Rent $P$ and Ghosh $S$. Understanding the Cash-Less Nature of Government-Sponsored Health Insurance Schemes: Evidence From Rajiv Gandhi Jeevandayee Aarogya Yojana in Mumbai. SAGE 
Open.2015; October-December: 1-10.

24. Palacios R. India's health insurance scheme for the poor: evidence from the early experience of the Rashtriya Swasthya Bima Yojana. In: Palacious R, Das J, Sun C.eds. India's Health Insurance Scheme for the Poor: Evidence from the Early Experience of the Rashtriya Swasthya Bima Yojana. Centre for Policy Research; 2011:280.

25. La Forgia G, Nagpal S. Government Sponsored Health Insurance in India- Are You Covered? Washington D.C. World Bank. 2012.

26. Garg, Samir et al. Utilisation and Financial Protection for Hospital Care under Publicly Funded Health Insurance in Three States in Southern India. BMC Health Services Research. 19, 1004

(2019) December 2019. DOI : 10.1186/s12913-019-4849-8 BHSR-D-19-01107R3

27. Fan VY, Karan A, Mahal A. State health insurance and out-of-pocket health expenditures in Andhra Pradesh, India. International journal of health care finance and economics. 2012; 12(3):189-215. https://doi.org/10.1007/s10754-012-9110-5 PMID: 22767078

28. Rao M, Katyal A, Singh P, Samarth A, Bergkvist S, Kancharla M. et al. Changes in addressing inequalities in access to hospital care in Andhra Pradesh and Maharashtra states of India: a difference-in-differences study using repeated cross-sectional surveys. BMJ open. 2014; 4(6):e004471. https://doi.org/10. 1136/bmjopen-2013-004471 PMID: 24898084

29. Sood N, Bendavid E, Mukherji A, Wagner Z, Nagpal S and Mullen P. Government health insurance for people below poverty line in India: quasi-experimental evaluation of insurance and health outcomes. British Medical Journal. 2014; 349: g5114. https://doi.org/10.1136/bmj.g5114 PMID: 25214509

30. Dhanaraj Economic vulnerability to health shocks and coping strategies: evidence from Andhra Pradesh, India. Health Policy and Planning, Volume 31, Issue 6, July 2016, Pages 749-758, https://doi.org/10.1093/heapol/czv127

31. Government of Chhattisgarh - Department of Health and Family Welfare. Tender Document for Selection of Insurance Company for the implementation of Ayushman Bharat - National Health Protection Mission (AB-NHPM) \& Mukhyamantri Swasthya BimaYojana (MSBY) In the State Chhattisgarh. July 2018.

32. Department of Health and Family Welfare Government of Chhattisgarh. List of Hospitals under Ayushman Bharat PMJAY \&MukhyamantriSwasthyaBimaYojana, Chhattisgarh as on 7/12/2018 http://cg.nic.in/healthrsby/RSBY_Documents/ABPMJAYHospitalsNoneDentalCG.pdf Accessed on 5th September, 2019

33. Department of Health and Family Welfare Government of Chhattisgarh. Financial Year Wise Claim Summary RSBY and MSBY C.G. (Updated 31/12/2018. http://cg.nic.in/healthrsby/reports/Dashboardpublic.aspx. Accessed on 5th September, 2019

34. Acharya A, Vellakkal S, Taylor F, Masset E, Satija A, Burke M, et al. Impact of national health insurance for the poor and the informal sector in low-and middle-income countries: a systematic review. London: EPPI-Centre, Social Science Research Unit, Institute of Education, University of London. 2012. 
35. Government of India. NSS 60th Round: Jan - June 2004. Morbidity, Health Care and the Condition of the Aged. Ministry of Statistics and Programme Implementation. National Sample Survey Organization. http://mospi.nic.in/sites/default/files/publication_reports/507_final.pdf. Last accessed 1st November, 2019

36. Government of India. NSS 60th Round: Jan - June 2004. Ministry of Statistics and Programme Implementation. National Sample Survey Organization. Dataset. Available at: http://microdata.gov.in/nada43/index.php/catalog/105. Last accessed 1st November, 2019

37. Gol (Government of India). Health in India-NSS 71st Round (January to June 2014). (Ministry of Statistics and Programme Implementation. National Sample Survey Organisation NSSO). 2016. Last accessed 1st November, 2019

38. Government of India. 2015. Key Indicators of Social Consumption in India - Health. NSS 71st Round. Jan-Jun 2014. Ministry of Statistics and Programme Implementation. National Sample Survey Office. 2015. Available at: http://mospi.gov.in/sites/default/files/publication_reports/nss_71st_ki_health_30june15.pdf. Last accessed 1st November, 2019

39. Government of India. Social Consumption in India - Health. NSS 71st Round. Jan-Jun 2014. Ministry of Statistics and Programme Implementation. National Sample Survey Office. 2015. Available at: http://microdata.gov.in/nada43/index.php/catalog/135. Last accessed 1st November, 2019

40. Wagstaff A, Doorslaer E. "Catastrophe and Impoverishment in Paying for Healthcare: With Applications to Vietnam 1993-98". Health Economics. 2003;(12):921-34.

41. Kastor A, Mohanty SK. Disease-specific out-of-pocket and catastrophic health expenditure on hospitalization in India: Do Indian households face distress health financing? PLoS One. 2018; 13(5):e0196106. doi:10.1371/journal.pone.0196106.

42. Labour Bureau. Statistical Data for Labour - Index Numbers. Ministry of Labour, Government of India. http://labourbureau.gov.in/LBO_indtab_Feb_2019.pdf Accessed 10th December, 2019.

43. Giedion U, Alfonso AE, Díaz Y. The Impact of Universal Coverage Schemes in the Developing World: A Review of the Existing Evidence. UNICO Studies Series 25. The World Bank; 2013. Washington DC, January 2013

44. Wagstaff, A and Lindelow, M. Can insurance increase financial risk? The curious case of health insurance in China. Journal of Health Economic. 2008. 27 (2008) 990-1005

45. Leewu F, Vaessen J. NONIE Guidance on Impact Evaluation. Network of Networks on Impact Evaluation, Independent Evaluation Group. Washington DC. 2009.

46. Rukundo EN. Does Community-Based Health Insurance Reduce Child Stunting? Evidence from a Cross-sectional Survey in Rural Uganda. ZEF Bonn Center for Development Research Bonn University. 1 May 2017.

47. Galarraga O, Sosa-Rubi SG, Salinas-Rodrıguez A, Sesma-Vazquez S. Health insurance for the poor: impact on catastrophic and out-of-pocket health expenditures in Mexico. Eur J Health Econ (2010) 
11:437-447 DOI 10.1007/s10198-009-0180-3

48. Aryeetey GC, Westeneng J, Spaan E, Jehu-Appiah C, Agyepong IA, Baltussen R. Can health insurance protect against out of-pocket and catastrophic expenditures and also support poverty reduction?

Evidence from Ghana's National Health Insurance Scheme. International Journal for Equity in Health (2016) 15:116 DOI 10.1186/s12939-016-0401-1

49. 'OVERID': module to calculate tests of overidentifying restrictions after ivreg2, ivreg29, ivregress, ivProbit, ivtobit, reg3. Last accessed October 10, 2018.

50. Baum, C.F. An Introduction to Modern Econometrics Using Stata. Stata Press; 2006

51. Gertler, P. and Solon, O. Who Benefits From Social Health Insurance in Developing Countries? University of California at Berkeley; 2000.

52. Nandi S, Schneider H. When state-funded health insurance schemes fail to provide financial protection: An in-depth exploration of the experiences of patients from urban slums of Chhattisgarh, India. August 2019. Global Public Health. DOI: 1080/17441692.2019.1651369

53. Mathauer I., Dkhimi F. Analytical guide to assess a mixed provider payment system. A guidance document, Department of Health Systems Governance and Financing, Geneva: World Health Organizaion; 2018 (WHO/UHC/HGF/Guidance/19.5). License: CC BY-NC-SA 3.0 IGO

54. Hanson, K. Moving Towards a Purchasing Model in Low and Middle Income Countries? Available from: http://resyst.Ishtm.ac.uk @RESYSTresearch. Accessed 1st November, 2019.

\section{Supplementary Files}

This is a list of supplementary files associated with this preprint. Click to download.

- SI.zip 